\title{
El orientalismo en algunos relatos de Jorge Luis Borges
}

\section{Fatma Adel Mostafa Mahmoud}

Resumen

En este trabajo abordamos el tema del orientalismo en algunos cuentos de Jorge Luis Borges. Intentemos subrayar y analizar el papel que juega Las mil y una noches en la obra y pensamiento del gran escritor argentino. "Abenjacán el Bojarí, muerto en su laberinto" y "Los dos reyes y los dos laberintos" son dos de los relatos de Borges que tienen elementos orientales y tratan del mismo tema: el laberinto.

Palabras claves: Jorge Luis Borges, el orientalismo, Las mil y una noches, el laberinto, la cultura árabe.

\section{Abstract}

This article tackles the topic of Orientalism in some stories of Jorge Luis Borges. We intend to emphasize and analyze the role that The Thousand and One Nights plays in the work and literary thought of the great Argentinian author. "Ibn Hakam al Bokhari, Murdered in his labyrinth" and "The two kings and the two labyrinths" are two of the stories of Borges that contain elements Orientals and deal with the same topic: the labyrinth.

Key words: Jorge Luis Borges, Orientalism, The Thousand and One Nights, the labyrinth, the Arabic culture.

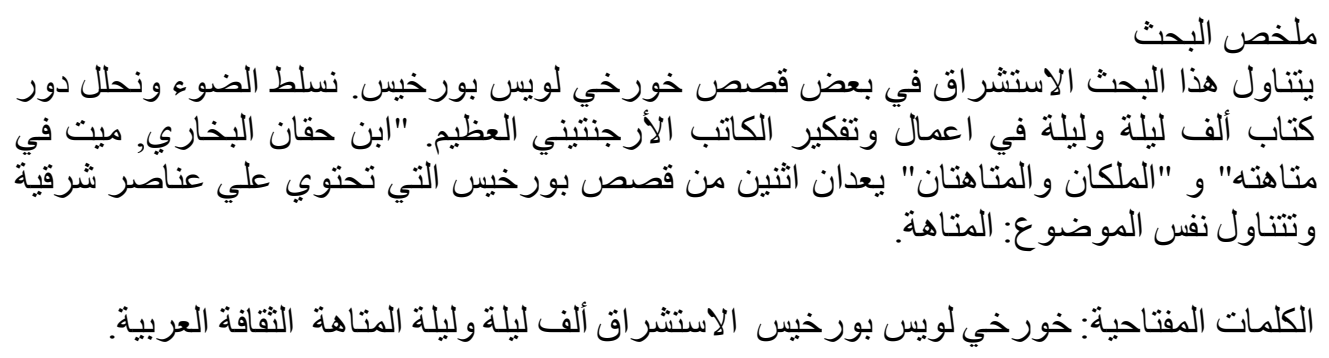




\section{Introducción}

En este trabajo proponemos analizar uno de los temas más transcendentes del gran autor argentino: el orientalismo. Partiendo de algunos relatos de Borges intentaremos demostrar la presencia de este concepto en sus obras, sobre todo, en Ficciones y El Aleph, que incluyen varios aspectos de la cultura árabe en la narrativa borgeana. Durante toda su vida Borges sintió una fuerte pasión por la cultura. El ámbito familiar ha permitido a Borges tomar contacto y conciencia de varias culturas. Entre estas culturas destacan su admiración por la cultura árabe. Hablamos también sobre el origen de la fascinación del autor por el orientalismo que pasó a formar parte de su narrativa. Abordamos el papel que juega Las mil y una noches en la obra y el pensamiento de Jorge Luis Borges. Las mil y una noches es una de las obras más importantes e influyentes de la literatura universal. Se trata de varios cuentos y leyendas de origen árabe, hindú y persa. Existen múltiples versiones y traducciones de esta obra. A finales del siglo XIX, apareció la primera traducción al español. Además, analizamos detalladamente dos cuentos: "Abenjacán el Bojarí, muerto en su laberinto" y "Los dos reyes y los dos laberintos" que tienen mucho detalles en común. Ambos relatos tienen elementos orientales y tratan del mismo tema: el laberinto, un tema muy antiguo y frecuente en la narrativa borgeana.

El objetivo principal de nuestro trabajo es ahondar en las bases del orientalismo en la narrativa de Jorge Luis Borges. Dedicaremos parte de este trabajo a estudiar las vinculaciones entre dos relatos de Borges que contienen el elemento oriental. 


\section{El origen del orientalismo en América latina}

El Oriente fue conocido en América Latina a través de sus cuentos populares, entre ellos destacan Las mil y una noches y Calila y Dimna. Muchos autores se interesan por los temas orientales en sus diferentes aspectos: culturales, literarios, históricos y políticos. El orientalismo tiene importante impacto en el pensamiento de numerosos escritores.

A inicios del siglo XX numerosos profesores, políticos, críticos, filós ofos, reporteros y escritores comenzaron a apasionarse por la inagotable geografía cultural del vasto Oriente. La atracción ejercida por este universo no estaba tan solo animada por las febriles lecturas de Las mil y una noches, como había sucedido en gran medida con Leopoldo Lugones y la generación modernista ${ }^{1}$.

El catedrático Axel Gasquet estudia los discursos producidos por el mundo hispanoamericano sobre el Oriente y el contexto cultural y social de la historia del orientalismo en Argentina. El escritor ofrece una historia cultural del orientalismo argentino. Se señala los cambios que aparecieron en la cultura argentina a fines del siglo XIX. Gasquet refiere a la desilusión cultural causado por La Primera Guerra Mundial y su manifestación en obras de los autores de este período. Él señala al escritor alemán Arthur Schopenhauer como el padre de la escuela orientalista alemana.

Las filosofías orientales empezaron a gravitar abiertamente en el pensamiento moderno de Occidente a partir de Arthur Schopenhauer, que estuvo fuertemente influenciado por las tradiciones filosóficas hindúes u budistas. La obra juvenil más importante del filósofo idealista fue El mundo como voluntad y representación, que en 1819 acusaba ya el notable impacto de dichas herencias extrañas a la tradición europea ${ }^{2}$.

La obra de Schopenhauer y su interés oriental valora positivamente al pensamiento de Jorge Luis Borges. Gasquet comenta:

Es sabido que el pensamiento de Schopenhauer tuvo un fuerte impacto en el joven Borges. Mientras la Primera Guerra Mundial asolaba a Europa, el adolescente porteño frecuentó la obra del alemán en el oasis ginebrino. Dicha lectura borgeana dejará una fuerte impronta en su obra literaria y ensayística, de marcado carácter idealista, huella que él mismo reconoció en numerosas circunstancias ${ }^{3}$.

En cuanto al autor argentino, uno de los temas más transcendentes de la narrativa de Borges es el orientalismo que constituye un eje temático y estético principal en la obra del autor argentino. La influencia orientalista nace desde su infancia y juventud. En efecto, el ámbito familiar ha permitido a Borges tomar contacto y conciencia de varias culturas. Sonia Betancort afirma que:

Las sorprendentes imágenes y las numerosas lecturas orientalistas lo acompañaron desde sus primeras inmersiones en el mundo de la literatura, 
gracias a dos influencias familiares, la de su padre y la de su abuela paterna, apoyos que favorecieron la conquista del horizonte del precoz literario que lograría la traducción de un cuento repleto de imágenes de Oriente, "El Príncipe Feliz" de Oscar Wilde, que Georgie publicó con sólo once años ${ }^{4}$.

Cabe destacar que el contacto de Borges con la cultura oriental nace en su infancia. Sonia Betancort Santos comenta que "con el aprendizaje de las primeras letras, la fascinación por Oriente, a un tiempo apasionante y aterrador, se instaló para siempre en la imaginación de Jorge Luis Borges" ${ }^{5}$. En el libro Orientalismo, Edward Said nos habla del conocimiento de lo oriental. Nos define el Orientalismo como una proyección de Occidente sobre Oriente y su voluntad de gobernarlo. Según el autor, hablando de orientalismo nos referimos no solo a un área geográfica que consta de Asia y el Este, sino también el norte africano. En su sentido más general el orientalismo incluye a la India. En efecto, el orientalismo ya había producido un gran impacto en Europa del siglo XIX. El erudito Edward Said publicó un libro polémico sobre Oriente. Said comenta: "una verdadera epidemia de Oriente en Europa que afectó a todos los grandes poetas, ensayistas y filósofos del momento"6.

Borges utiliza las fuentes orientales, árabes e islámicas frecuentemente. Entre estas fuentes destacan Las mil y una noches, El Corán y las historias populares árabes. La primera se considera para Borges "uno de los títulos más hermosos del mundo" .El autor argentino tiene su propia concepción de oriente. En Siete Noches Borges dice sobre el oriente:

¿Qué es el Oriente? Si lo definimos de un modo geográfico nos encontramos con algo bastante curioso, y es que parte del Oriente sería el Occidente o lo que para los griegos y romanos fue el Occidente, ya que se entiende que el Norte de África es el Oriente. Desde luego, Egipto es el Oriente también, y las tierras de Israel, el Asia Menor y Bactriana, Persia, la India, todos esos países que se extienden más allá y que tienen poco en común entre ellos. Así, por ejemplo, Tartaria, la China, el Japón, todo eso es el Oriente para nosotros. Al decir Oriente creo que todos pensamos, en principio, en el Oriente islámico, y por extensión en el Oriente del norte de la India ${ }^{7}$.

Borges considera estos escritos como fuente de inspiración. Su admiración de otras culturas representa la sensación de perderse en otro mundo en donde cosas mágicas pueden suceder. Es importante recordar que los árabes llegaron a la Península Ibérica y estuvieron allí a lo largo de nueve siglos. Así, al entrar España en la carrera imperialista ya se contaba en cierto sentido con una influencia cultural árabe. Luce Baralat habla sobre el tema del oriente en Borges y sobre todo, la influencia de la literatura árabe en la narrativa borgeana. Entre los cuentos con el carácter árabe destaca "Abenjacán el Bojarí, muerto en su laberinto". La autora comenta: 
El símbolo del infinito laberinto verbal es central en "Abenjacán el Bojarí, muerto en su laberinto". La historia abre con un versículo de la azora XIX (40) del Corán que alude a quienes, como la araña, construyen una red laberíntica para atrapar a sus víctimas. El versículo apunta en este relato a la literatura árabe, concretamente, a Las mil y una noches. Dos amigos ingleses, Dunraven y Unwin, exploran un misterioso laberinto circular construido por Abenjacan el Bojarí en Cornwall, tierra célebre por el contrabando. Como la red de la araña coránica, el laberinto era circular y tenía un solo cuarto central ${ }^{8}$.

Carmen Espejo Cala habla sobre la fascinación del autor argentino por la cultura árabe. La autora aclara la concepción de "Oriente" para Borges. Cala comenta:

El Oriente de Borges es amplio y variopinto... Incluye a China y a Japón, con sus respectivas religiones, literaturas, costumbres, ideologías; coloca en lugar destacado a Persia, sus ciudades mitológicas y sus poetas profundos; no olvida ni a Israel ni a la India. Pero el término "Oriente" designa fundamentalmente, en el atlas literario del argentino a la cultura árabe ${ }^{9}$.

Entre las pruebas de la existencia de Oriente en la narrativa borgeana es la composición de la Antología de la literatura fantástica publicada en 1940 en colaboración con Adolfo Bioy Casares y Silvina Ocampo que contiene varios componentes de historia oriental, empezando con un relato japonés. Además de los varios cuentos escritos por Borges como por ejemplo: "La busca de Averroes", "El Zahir", "Abenjacán el Bojarí, muerto en su laberinto" y " Tlon, Uqbar, Orbis Tertius".

Susanna Regazzani aborda el tema de Oriente de Borges en su artículo mencionando los aspectos más importantes de su vinculación con el mundo oriental. La autora demuestra que la clave orientalista borgeana reside en la búsqueda de lo desconocido. Regazzani aclara el concepto del Orientalismo en Borges:

Cuando se habla de «orientalismo», en Borges, se habla de una miradalectura, no fascinado por el exotismo del otro, ni hegemónico: el Oriente no reside en lo que es extraño y maravilloso, se trata de ocupar un territorio desconocido, de habitarlo, como la página de escribir. Es el encuentro con una idea diversa, fascinante, recuperada y reinventada por el escritor: es un modo de escapar del canon, de la norma, de dejarse invadir por el territorio desconocido. Borges está lejos del viejo concepto de Orientalismo, en este caso parece más bien acercarse a la propuesta de nuestra contemporaneidad ${ }^{10}$.

Desde el punto de vista de Regazzani, el Oriente de Borges es:

El Oriente de Jorge Luis Borges, además de ser un elemento fantástico y un instrumento filosófico para eliminar la identidad individual, es también un fruto textual de viajes literarios, una adquisición de segundo o tercer grado, trasversal a los géneros mismos. De hecho, esto desemboca en 
varias instituciones literarias, pasa indistintamente de los libros de ensayos a la poesía o a la prosa, leídos en traducciones, adoptando una escritura descentralizada, con el fin de crear una nueva forma de lectura, de escritura, y haciendo emerger, de este modo, a una literatura diversa, móvil, siempre activa, nómade y antiautoritaria ${ }^{11}$.

Además, la autora habla sobre la relación entre Oriente y América Latina. Diversos países latinoamericanos se dedican al estudio de la política, la economía, la cultura y la sociedad de Medio Oriente. Se considera que los antecedentes históricos del vínculo entre América Latina con Medio Oriente representa el fundamento substancial a partir del cual se comienza entablar los primeros contactos, iniciando así un proceso de acercamiento entre ambas regiones. Regazzani comenta:

Existe, pues, un vínculo entre Hispanoamérica y Oriente evidenciado ya en las crónicas del descubrimiento y de la conquista, donde el imaginario utópico se aplicaba a la realidad de nuevos paisajes. Las tierras conocidas en el pasado y olvidadas con el pasar del tiempo, se vuelven a descubrir. Un Nuevo Mundo, por lo tanto, tan intenso como metáfora de la utopía, que según el pensamiento renacentista es también metáfora de Oriente. Nacida como tierra del este, América Latina es originariamente englobada y representada a través de símbolos orientales, comenzando con nombre: Las Indias. Y es sorprendente, pero verdadero, que los orientales (chinos, japoneses, árabes, etcétera) son hoy un componente importante de la población de aquel continente ${ }^{12}$.

En cuanto a la literatura, es notorio que hay muchos relatos que contienen elementos orientales en la narrativa borgeana. El elemento oriental para el escritor argentino es un artificio que contribuye a la formación de sus obras. Desde nuestro punto de vista este elemento fue de gran utilidad en la mayoría de sus obras. 


\section{Las mil y una noches como fuente de inspiración}

En el primer libro narrativo de Borges Historia universal de la infamia que contenía dos relatos versionados de Las mil y una noches, "La cámara de las estatuas" e "Historia de los dos que soñaron", una historia ambientada en el Sudán musulmán y otra titulada "Un doble de Mahoma" inspirada en una reflexión de Swedenborg ${ }^{13}$. A partir de entonces Borges localizará sus relatos en Babilonia, Babel, Alejandría, Alhambra y también utilizará nombres como Averroes, Abenjacán el Bojarí y Almotásim. Ahora bien no se puede hablar del impacto de Oriente sin mencionar Las mil y una noches y sobre todo de las numerosas traducciones que se han hecho de ella. Borges conoce tan profundamente la colección de cuentos árabes que utilizó sus aventuras como fuente de inspiración en su narrativa literaria. El propio autor pronunció una conferencia sobre la obra, recogida luego entre los ensayos de Siete noches. Sobre esta obra Borges dice:

En el título de Las mil y una noches hay algo muy importante: la sugestión de un libro infinito. Virtualmente, lo es. Los árabes dicen que nadie puede leer Las mil y una noches hasta el fin. No por razones de tedio: se siente que el libro es infinito. Tengo en casa los diecisiete volúmenes de la versión de Burton. Sé que nunca los habré leído todos pero sé que ahí están las noches esperándome; que mi vida puede ser desdichada pero ahí estarán los diecisiete volúmenes; ahí estará esa especie de eternidad de Las mil y una noches del Oriente ${ }^{14}$.

Entre 1954 y 1955 se publicó en México la que se declaraba primera traducción completa al castellano de Las mil y una noches. Dicha versión fue saludada por Jorge Luis Borges, el gran conocedor de la obra maestra árabe en el ámbito del castellano, quien se declaró, en más de una ocasión, admirador de esta obra maravillosa. Se trata de varias narraciones relatadas por Scherezade con la técnica de cajas chinas. El rey Schariar, tras sufrir las infidelidades de su esposa, decide casarse cada día con una joven virgen y matarla a la mañana siguiente. Para impedir que todas las chicas del reino mueran, la joven Scherezade, como voluntaria, se casó con el rey. La muchacha cuenta al rey una historia cada día sin acabarla. Scherezade salva cada noche su vida a través de saber encadenar una historia con otra y saber interrumpirse en el momento justo. Las historias se prologarán a lo largo de mil y una noches. Al final, Schariar es cautivado.

Salvador Martín, reconocido como traductor literario especializado en el estudio de la historia de la traducción, se ahonda sobre un tema muy importante: la retraducción de clásicos y sobre todo de Las mil y una noches. El autor afirma que Borges fue un gran admirador de esta obra espectacular que llama la atención de muchos escritores y críticos. Martín comenta:

Borges fue el gran conocedor y valedor de las Noches durante las décadas centrales del siglo XX, digamos que entre los años treinta y los ochenta, en el ámbito del castellano y con trascendencia internacional. Y el gran escritor argentino, que conocía personalmente a Cansinos, de quien se 
consideraba admirado discípulo, escribió al menos en tres ocasiones elogios de la versión de las Noches que este llevó a cabo ${ }^{15}$.

La traducción francesa de Las mil y una noches de Monsieur Antoine Galland es la principal responsable de la fama universal de la que esta obra goza. Se trata de un conjunto de cuentos con los que se divierten durante las largas noches en aquel país. Italo Calvino afirma: "No en vano a comienzos de ese siglo la traducción francesa de las Mil y una noches por Antoine Galland abrió a la fantasía occidental los horizontes de lo maravilloso oriental: alfombras voladoras, caballos voladores, genios que salen de lámparas" ${ }^{16}$. Galland publicó su primera traducción de esta obra del árabe al francés en el año 1704. El autor necesitó trece años para completar la edición de sus traducciones que terminó en 1717. Axel Gasquet afirma que:

Comúnmente se acepta que la primera traducción integral de la obra fue realizada por el francés Antoine Galland, bajo el reinado de Luis IV, publicada en doce volúmenes entre 1704 y 1717. Galland vertió al francés una versión árabe traída por él de Alepo, Siria, manuscritos de los que salieron los primeros seis volúmenes ${ }^{17}$.

Esta colección de cuentos contiene historias de diferentes características, del amor, de la vida cotidiana de la gente del Oriente, de las leyendas árabes y algunos casos trágicos y otros cómicos. Además, existe una mezcla de historias reales con otros fantásticos. A finales del siglo XIX, apareció la primera traducción de Las mil y una noches al español. En el siglo siguiente, el valenciano Vicente Blasco Ibáñez tradujo la obra del francés.

Maryam Ghafouri aborda la obra en su tesis doctoral. Ghafouri ofrece una breve historia de esta obra y se señalan sus orígenes. Además, habla del contexto social y político de los años en que esta fue redactada. Cabe señalar que las historias de Las mil y una noches tratan de varios asuntos sociales y personales. La autora refiere al impacto y la difusión de la obra en la literatura tanto oriental como occidental. Existe una influencia notable de esta obra en la narrativa de Jorge Luis Borges. Ghafouri comenta:

Borges tiene unos mundos literarios muy definidos, y Las mil y una noches ocupan un lugar de honor entre sus fuentes de conocimiento y de inspiración. Parece ser que Borges incluyó esta obra entre sus lecturas favoritas y le otorgó un espacio privilegiado entre los numerosísimos libros de su biblioteca personal. Borges se ocupó de los textos de Las mil y una noches en su narrativa y también en sus trabajos con forma de ensayo ${ }^{18}$.

La autora dice sobre Borges:

Borges no copia a los cuentos de Las mil y una noches con un afán de orientalismo. Como autor muy apegado a la mejor tradición literaria occidental, prefiere crear un universo de mezcla, de mestizaje, que resume 
lo mejor de Oriente y de Occidente. La modernidad ensalza la racionalidad como método para el saber y para su expresión. La posmodernidad ataca el enfoque hiperrealista. De una obra clásica con una gran tradicional oral como el texto de Las mil y una noches cabría esperar una descripción casi descarnada de la realidad, que la asimilará a las más grandes narrativas naturalistas. Por el contrario, Las mil y una noches se fundan en un espíritu mágico moralizante. Quizás por eso Borges considere que esta obra es algo similar a un auténtico modelo literario. La literatura no se identifica con narrar lo existente, sino que busca argucias expresivas para ahondar en el ser humano a través de elementos que van más allá de la ramplona realidad ${ }^{19}$.

Cabe destacar que las primeras lecturas de Borges en torno a Las mil y una noches se basen en la traducción inglesa de Richard ingente, quien utilizó textos árabes para su trabajo. Viajero vinculado con el Oriente y los laberintos. En "Historia de los dos reyes y los dos laberintos" Borges transcribió una nota que atribuye a Burton, traductor de Las mil y una noches, en la cual se recrea la idea de que el universo es un laberinto. La traducción de Burton es una de las fuentes favoritas de Borges. Como afirma Sonia Betancort: "No cabe duda de que la asombrosa vida y obra de Burton conmovieron a Georgie, cuyo pensamiento mantuvo siempre presente la frescura transgresora de la traducción burtoniana ${ }^{20 "}$. La autora añade mencionando que Burton fue uno de los eruditos que tuvieron un papel muy significante en abarcar los tesoros del Oriente.

"Abenjacán el Bojarí, muerto en su laberinto" y "Los dos reyes y

los dos laberintos" dos caras de la misma moneda

"Abenjacán...", el relato comienza con Dunraven y Unwin, dos jóvenes que tratan de dilucidar las misteriosas circunstancias que rodean la muerte del rey Abenjacán el Bojarí, a manos de su primo Zaid. La respuesta al porqué de este misterio debe aclarar los siguientes puntos: "En primer lugar, esa casa es un laberinto. En segundo lugar, la vigilaban un esclavo y un león. En tercer lugar, se desvaneció un tesoro secreto. En cuarto lugar, el asesino estaba muerto cuando el asesinato ocurrió" (O. C. I, p. 600). Dentro del laberinto, escenario de los hechos, Unwin y Dunraven tratan de imaginar la escena de la tragedia. Cada uno de los dos amigos intenta descifrar el misterio. Se produce en este relato, la temática del desdoblamiento que convierte al verdugo en víctima y a la víctima en verdugo, con toda la cadena de consecuencias que esto implica: incomunicación, soledad, pérdida de la propia identidad. El relato abre con un versículo de la azora XIX (40) del Corán. Este versículo apunta a la literatura árabe y a la gran influencia que tiene en el autor argentino. Luce López Baralt aborda el tema de la fascinación que siente Borges por el Oriente. La investigadora estudia la influencia de la literatura árabe en la narrativa borgeana. 
El análisis de "Abenjacán el Bojarí, muerto en su laberinto" pone de manifiesto la apropiación de la literatura árabe por parte de Occidente. La investigadora sostiene que a través de las traducciones, a menudo "babélicas", de originales árabes como las Mil y una noches, Oriente "atrapa" a los lectores europeos en su misterioso, interminable laberinto ${ }^{21}$.

Borges refiere a una parte del versículo que apunta a la fragilidad de la casa de la araña que es una figura adecuada del laberinto. Cabe señalar que lo más destacado en esta historia es la concepción del desierto como laberinto. Además de la presencia de varios elementos orientales. En El Aleph encontramos varios relatos que tratan el tema de la cultura árabe: "La busca de Averroes", "El Zahir", "El Aleph", "Abenjacán el Bojarí, muerto en su laberinto" y "Los dos reyes y los dos laberintos". En cuanto al último, empieza en un laberinto artificial, construido por el hombre y termina en el laberinto espontáneo del desierto. Ambos relatos contienen los elementos compositivos de igual manera y están dominados por las mismas leyes: el binarismo y las diferentes posibilidades combinatorias. Steven Boldy cometa: "Para Borges, sin embargo, el cuento se abre necesariamente a otros cuentos, es el centro de una red de conexiones. "Los dos reyes y los dos laberintos" es una mise en abyme ${ }^{22}$ de otro cuento: "Abenjacán el Bojarí, muerto en su laberinto"23. Este relato no ha llamado mucho la atención de los críticos del autor argentino. El autor comenta que sus amigos lectores le aseguran que:

Abenjacán el Bojarí, muerto en su laberinto no es (me aseguran) memorable a pesar de su título tremebundo. Podemos considerarlo una variación de Los dos reyes y los dos laberintos que los copistas intercalaron en las 1001 Noches y que omitió el prudente Galland. (O. C. I, p.629).

Los dos relatos tienen muchos elementos en común. Ambas historias se consideran como dos caras de la misma moneda y tratan del mismo tema: el laberinto. Es notorio que es uno de los temas más frecuentes de la narrativa borgeana. Otro elemento es el desierto que es una de las señas de identidad de la cultura árabe.

En "Abenjacán el Bojarí, muerto en su laberinto", Inglaterra oficia de espacio laberíntico. En el segundo relato "Los dos reyes y los dos laberintos", Babilonia y Arabia constituyen los dos laberintos. Pero lo que más interesa aquí, más allá de la onomástica árabe, es la inscripción del desierto, espacio por excelencia de la tradición islámica, en el registro de los laberintos ${ }^{24}$.

La historia de "Los dos reyes y los dos laberintos" se trata de un rey árabe que utiliza el desierto como laberinto donde no hay escaleras, ni truculentos, pasadizos, donde todos los puntos están comunicados, donde no hay pistas ni hilos que el hombre puede seguir. Es decir, no existe salida. Es un relato brevísimo y muy intenso que se considera como una versión de "Abenjacán...". Existe una nota a pie de página que muestra la vinculación 
entre los dos relatos. "Ésta es la historia que el rector divulgó desde el púlpito (O. C. I, p. 607)".

Cabe señalar que la relación entre ambos cuentos es significativa. Los principios que deben regir la construcción de cada laberinto son presentes en los dos relatos. El laberinto ideal es aquel que se basa en una aparente simple pero en realidad es complejo y es un símbolo del infinito. Tenemos en cuenta que Borges intenta desde el principio atribuir "Los dos reyes y los dos laberintos" a "Abenjacán...". Las mil y una noches son la fuente de inspiración de ambos cuentos, son historias ambientadas en el MedioOriente. 


\section{Conclusiones}

El orientalismo en su sentido amplio se trata de toda representación cuya temática aluda a países o a formaciones históricas y culturales. La atracción apasionada por el Oriente tenía una larga influencia en muchos autores. No resulta sorprendente que el autor argentino ha sido influido por varias culturas diferentes como consecuencia de sus viajes por diferentes países y el haber aprendido varios idiomas, ha tenido la oportunidad de interactuar con gente de diferentes culturas. Estas experiencias acrecentaron su interés de saber más sobre el mundo oriental. Una primera ojeada a algunas obras de Jorge Luis Borges revela su preocupación por el Oriente. Pasando de la ojeada superficial a la lectura atenta de los cuentos y ensayos que contienen elementos orientales se nota que el mundo oriental ha influido mucho en el pensamiento del gran autor argentino. Borges está lejos del viejo concepto de Orientalismo. El orientalismo de Jorge Luis Borges constituye en el encuentro con una idea fascinante recuperada por el escritor, igual de ocupar un territorio desconocido y el intento de habitarlo.

Quien conoce Las mil y una noches entenderá de una manera más precisa la obra de Jorge Luis Borges. En las páginas de este trabajo se ha tratado como los textos orientales de esta obra han dejado una huella clara en la narrativa borgeana. Es notorio que esta obra ya ha ganado un lugar especial entre los clásicos de la literatura universal. La simplicidad de las historias y la variedad de las tramas han provocado que autores como Jorge Luis Borges ha preocupado por estas narraciones orientales.

Hay una gran semejanza entre los dos cuentos de Borges: "Abenjacan el Bojarí, muerto en su laberinto" y "Los dos reyes y los dos laberintos". Ambos relatos son dos caras de la misma moneda. Contienen elementos que reflejan la dignidad de la cultura oriental. El tema principal de ambos cuentos es el laberinto que es el eje principal en la mayoría de las obras del autor argentino. Se muestra como símbolo de confusión, de lo enigmático del destino humano, de soledad y de búsqueda de la entidad. Borges utiliza el desierto como un laberinto natural, gran laberinto complejo donde no existen paredes, ni escaleras, ni puertas.

Otro aspecto importante es la influencia oriental que apareció en ambos relatos. A partir de los protagonistas de los cuentos y el uso del desierto árabe. "Abenjacán el Bojarí, muerto en su laberinto" contiene un epígrafe coránico que abre con la azora titulada La araña. Como resultado de nuestra investigación, concluimos que existen numerosas referencias a la cultura árabe y al Oriente en la narrativa de Borges. En otras palabras, la tradición árabe es muy presente en su narrativa de modo que afirma su afán por el orientalismo. 


\section{Bibliografía y fuentes de referencia}

Betancort Santos, Sonia: Oriente no es una pieza de museo. Jorge Luis Borges, la clave orientalista y el manuscrito de "Qué es el Budismo, tesis doctoral inédita dirigida por la Dra. Carmen Ruiz Barrionuevo, Salamanca, 2010 .

- Boldy, Steven: "Agua Quemada de Carlos Fuentes: cuento y cuartero" en América. Cahiers du CRICCAL, nº 18, tome. 1, 1997, pp. 203211. Disponible en página web: https://www.persee.fr/doc/ameri 0982-9237 1997 num 1811257. Fecha de consulta: 6/7/2020.

- Borges, Jorge Luis: "Cansinos y Las mil y una noches", en La Nación, Buenos Aires, 10 de julio de 1960. (Cito por la versión contenida en Textos recobrados (1956-1986), Barcelona, Random House Mondadori, 2011, pp. 51-53.

_ Borges, Jorge Luis: Obras Completas (I, II, III, IV, V), Buenos Aires, Emecé, 1997.

- Borges, Jorge Luis: Siete noches, México, Fondo de Cultura Económico, 1980.

- Calvino, Italo: Seis propuestas para el próximo milenio, traducción de Aurora Bernández, Madrid, Ediciones Siruela, 1994.

_ Espejo Cala, Carmen: "Borges y los árabes", en Philologia hispalensis, $\mathrm{n}^{\circ}$. 7, 1992, pp. 103-112. Disponible en página web: http://institucional.us.es/revistas/philologia/7/art 9.pdf. Fecha de consulta: 6/7/2020.

_ Fine, Ruth y Blaustein, Daniel: Introducción de La fe en el universo literario de Jorge Luis Borges, Hildesheim, Olms Verlag AG, 2012.

- Gasquet, Axel: El llamado de Oriente: historia cultural del orientalismo argentino (1900-1950), Ciudad Autónoma de Buenos Aires, Eudeba, 2015.

_ Gasquet, Axel: Oriente al Sur. El orientalismo literario argentino de Esteban Echeverría a Roberto Arlt, Bs.As. Eudeba, 2007.

- Ghafouri, Maryam: "Las mil y una noches como construcción intertextual e intercultural: sus vínculos con la literatura española", Tesis doctoral inédita dirigida por el Dr. Javier Rodríguez Pequeño, Madrid, 2017.

_ Lértora, Juan Carlos: "La estructura de la Mise en abyme" en fragmentos de Apocalipsis", Centro de investigaciones lingüístico literarias, Universidad Veracruzana, $\mathrm{n}^{\circ}$. 4, 1980, pp. 83-95. Disponible en página web: 
https://cdigital.uv.mx/bitstream/handle/123456789/6241/19804P83.pd f? sequence $=2$ \&isAllowed=y. Fecha de consulta: 8/8/2020.

_ Mbaya, Djibril: "La presencia de la tradición islámica en algunos relatos de Ficciones y El Aleph de Jorge Luis Borges" en Verbeia, $\mathrm{n}^{\circ}$. 1. Versión electrónica disponible en página web: https://www.ucjc.edu/wp-content/uploads/11.-Djibril-Mbaye.pdf.

Fecha de consulta: 7/7/2020.

_ Peña Martín, Salvador: "Las mil y una noches que llegaron de fuera: autoridad, progreso y ética en retraducción de clásicos (Una defensa de Cansinos), en De Homero a Pavese: hacia un canon iberoamericano de clásicos universales, Kassel, Reichenberger, 2017, pp. 137-158.

_ Regazzani, Susanna: "El oriente de Jorge Luis Borges", en Cuadernos literarios, Año. V, no . 8. 2009, pp. 73-81. Disponible en página web: http://repositorio.ucss.edu.pe/bitstream/handle/UCSS/313/Regazzoni Susana CL 08 articulo 2009.pdf?sequence=1\&isAllowed=y. Fecha de consulta: 8/7/2020.

_ Ruiz, Pablo Martín: "El último cuento policial de Borges y lo que había en el laberinto", en Variaciones Borges, no. 14, 2002, pp. 203 235. Disponible en página web: https://www.borges.pitt.edu/sites/default/files/1412.pdf. Fecha de consulta: 8/7/2020.

_ Said, Edward W.: Orientalismo, Barcelona, Debolsillo, 2013. Traducción de María Luisa Fuentes.

- Sorrentino, Fernando: Siete conversaciones con Jorge Luis Borges, Buenos Aires, Casa Pardo S. A., 1974.

_ Taboada, Hernán G. H.: Un orientalismo periférico: nuestra América y el islam, México, Universidad Autónoma de México, 2012.

_ Vazeilles, Julián: "El orientalismo en la obra de Borges: contrapuntos entre ensayos críticos de Beatríz Sarlo y de Christian Ferrer" en IX Jornadas de Sociología, Buenos Aires, Facultas de Ciencias Sociales, Universidad de Buenos Aires, 2011. Disponible en página web: https://www.aacademica.org/000-034/859. Fecha de consulta: 8/7/2020.

${ }^{11}$ Axel Gasquet: El llamado de Oriente: historia cultural del orientalismo argentino (19001950), Ciudad Autónoma de Buenos Aires, Eudeba, 2015, p. 29.

${ }^{2}$ Ibid., p. 23.

${ }^{3}$ Ibid., p. 25.

${ }^{4}$ Sonia Betancort Santos: Oriente no es una pieza de museo. Jorge Luis Borges, la clave orientalista y el manuscrito de "Qué es el Budismo, tesis doctoral inédita dirigida por la Dra. Carmen Ruiz Barrionuevo, Salamanca, 2010, p. 27. 
5 Ibídem., p. 27.

${ }^{6}$ Edward Said: Orientalismo, Barcelona, Debolsillo, 2013.p. 76.

7 J. L. Borges: Siete noches, México, Fondo de Cultura Económico, 1980, p. 23.

${ }^{8}$ Luce López Baralt: "Ultra Auroram et Gangem: Los laberintos islámicos de Jorge Luis Borges" en La fe en el universo literario de Jorge Luis Borges, Hildesheim, Olms Verlag AG, 2012, p. 119-120.

${ }_{9}^{9}$ Carmen Espejo Cala: "Borges y los árabes", en Philologia hispalensis, no . 7, 1992, p. 103. Disponible en página web: http://institucional.us.es/revistas/philologia/7/art_9.pdf. Fecha de consulta: 6/7/2020.

${ }^{10}$ Susanna Regazzani: "El oriente de Jorge Luis Borges", en Cuadernos literarios, Año. V, $\mathrm{n}^{\circ}$. 8.2009, p. 77. Disponible en página web:

http://repositorio.ucss.edu.pe/bitstream/handle/UCSS/313/Regazzoni_Susana_CL_08_articul o_2009.pdf?sequence=1\&isAllowed=y. Fecha de consulta: 8/7/2020.

${ }^{11}$ Ibid., p. 79.

12 Ibid., p. 75.

13 Carmen Espejo Cala: "Borges y los árabes", op., cit., p. 104.

${ }^{14}$ J. L. Borges: Siete noches, op., cit., p. 24.

15 Salvador Peña Martín: "Las mil y una noches que llegaron de fuera: autoridad, progreso y ética en retraducción de clásicos (Una defensa de Cansinos)", en De Homero a Pavese: hacia un canon iberoamericano de clásicos universales, Kassel, Reichenberger, 2017, p. 143.

${ }^{16}$ Italo Calvino: Seis propuestas para el próximo milenio, Madrid, Siruela, 2000, p. 36.

${ }^{17}$ Axel Gasquet: El llamado de Oriente..., op., cit., p. 40.

${ }_{18}$ Maryam Ghafouri: "Las mil y una noches como construcción intertextual e intercultural: sus vínculos con la literatura española", Tesis doctoral inédita dirigida por el Dr. Javier

Rodríguez Pequeño, Madrid, 2017, p.250.

${ }^{19}$ Ibid., p. 251.

${ }^{20}$ Sonia Betancort Santos: Oriente no es una pieza de museo, op., cit., p.36.

${ }^{21}$ Ruth Fine y Daniel Blaustein: Introducción de La fe en el universo literario de Jorge Luis Borges, Hildesheim, Olms Verlag AG, 2012, p. 12.

22 También titulado Puesta en abismo, se refiere a la técnica de insertar una historia dentro de otra. El término se deriva del francés. El escritor francés André Guide fue el primero que utilizó el término en la literatura. Se utiliza como un recurso estilístico. Véase: Juan Carlos Lértora: "La estructura de la Mise en abyme" en fragmentos de Apocalipsis", Centro de investigaciones lingüístico literarias, Universidad Veracruzana, nº 4, 1980, p. 83. Disponible en página web: https://cdigital.uv.mx/bitstream/handle/123456789/6241/19804P83.pdf?sequence=2\&is Allo wed=y. Fecha de consulta: 8/8/2020.

${ }^{23}$ Steven Boldy: "Agua Quemada de Carlos Fuentes: cuento y cuartero" en América. Cahiers du CRICCAL, $\mathrm{n}^{\circ}$. 18, tome. 1, 1997, p. 203. Disponible en página web: https://www.persee.fr/doc/ameri_0982-9237_1997_num_18_1_1257. Fecha de consulta: 6/7/2020.

${ }^{24}$ Djibril Mbaya: "La presencia de la tradición islámica en algunos relatos de Ficciones y El Aleph de Jorge Luis Borges" en Verbeia, $\mathrm{n}^{\circ}$. 1, p. Disponible en página web: https://www.ucjc.edu/wp-content/uploads/11.-Djibril-Mbaye.pdf. Fecha de consulta: $7 / 7 / 2020$. 